\title{
Hypertrophic scar fibroblasts accelerate collagen gel contraction
}

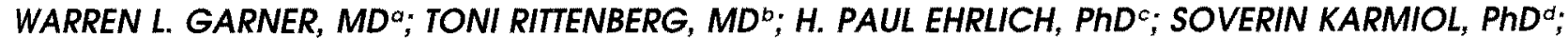 \\ JORGE L. RODRIGUEZ, MDa; DAVID J. SMITH, JR., MDa; SEM H. PHAN, MD, PhD ${ }^{d}$
}

\begin{abstract}
Excessive contraction of hypertrophic scar and subsequent contracture formation are a formidable problem after thermal injury. A comparison between fibroblasts from hypertrophic scar and normal skin was made with the use of fibroblast-populated collagen lattices as a measure of cellular generated contractile forces. Hypertrophic scar and normal skin fibroblasts were mixed with soluble tendon collagen and Dulbecco's modified Eagle medium supplemented with $10 \%$ serum, and contraction was measured by serial area measurements. Parallel experiments in the presence of transforming growth factor- $\beta$ or anti-transforming growth factor- $\beta$ antibody examined the role of this cytokine on lattice contraction. Transforming growth factor- $\beta$ activity was measured in an additional set of 10 biopsy specimens. Hypertrophic scar fibroblasts contract lattices at a significantly faster rate than do normal skin fibroblasts. Exogenous transforming growth factor- $\beta$ increased lattice contraction by normal skin fibroblasts but had little effect on hypertrophic scar cell-populated lattices. The addition of anti-transforming growth factor- $\beta$ antibody decreased lattice contraction by both cell types. Transforming growth factor $\beta$ activity was significantly increased in the hypertrophic scar biopsy specimens. Excessive scar contraction and post-burn scar contracture result from increased contraction forces generated by hypertrophic scar cells. This increased contractility appears to be mediated by increased endogenous presence of transforming growth factor- $\beta$. (WOUND REP REG 1995;3:185-91)
\end{abstract}

Interactions between cells and their surrounding matrix profoundly effect cell adhesion, migration, growth, and differentiation. ${ }^{1 \cdot 12}$ The nature and evolution of these relationships during wound healing are important to wound closure. The remodeling phase of wound healing includes the reorganization and reorientation of matrix fibrils synthesized during the proliferative phase of healing. ${ }^{13-15}$ The mechanisms and control of

From the Departments of Surgery and Pathology, University of Michigan Medical School, Ann Arbor. Mich.; and the Department of Surgery, Shriners Burn Institute, Massachusetts General Hospital, Boston, Mass. Department of Pediatric Surgery, M.S. Hershey Medical Center, Hershey, Pa.

Reprint requests: Warren L. Gamer, MD. University of Michigan Medical Center. 1500 E. Medical Center Dr., Ann Arbor, MI 48109-0033.

Copyright 1995 by the Wound Healing Society.

1067-1927/95\$3.00+ 0 36/1/65944

\begin{tabular}{|ll|}
\hline FBS & Fetal bovine serum \\
FPCL & Fibroblast-populated collagen lattice \\
HTS & Hypertrophic scar \\
NS & Normal skin \\
TGF- $\beta$ & Transforming growth factor- $\beta$ \\
\hline
\end{tabular}

these cell/matrix interactions during the remodeling phase of wound healing are not fully understood.

A simplified in vitro model to examine some of these interactions is the fibroblast-populated collagen lattice (FPCL) initially described by Bell, Ivarsson, and Merrill ${ }^{14}$ The FPCL is fabricated from cells, collagen, and serum-containing culture medium. It reduces in size to less than $20 \%$ of original size during a 1 - to 2week incubation period. ${ }^{14,16-18}$ Contraction of FPCL is modulated by the cell type composition, cell density, matrix protein composition and concentration, and cytokines. ${ }^{19-30}$ Because these factors modulate other cell/matrix interactions, it is likely that they would 
Table 1. Characteristics of patient population

\begin{tabular}{ccccc}
\hline Patient No. & Age (yr) & Gender & $\begin{array}{c}\text { Extent of burn } \\
\text { (\% body surface area) }\end{array}$ & Time after injury (mo) \\
\hline 1 & 7 & M & 21 & 19 \\
1 & 7 & M & 21 & 24 \\
2 & 38 & M & 75 & 19 \\
3 & 11 & M & 44 & 15 \\
4 & 8 & M & 25 & 84 \\
\hline
\end{tabular}

'A second biopsy sample was obtained from this patient at the indicated time after injury.

also influence the contraction and reorganization of proteins during wound healing.

After survival from major burn injury, the development of hypertrophic scar, scar contraction, and joint contracture are the major factors limiting complete recovery. ${ }^{31}$ These activities occur during the remodeling phase of burn wound healing and may represent altered cell/matrix interactions, resulting in distortions of normal wound and scar remodeling. Changes in the phenotype of fibroblasts within the scar tissue have been documented with regard to cytokine responses, which may explain the hypocellular and fibrotic nature of these lesions. ${ }^{32}$ Similar changes in cell/matrix interactions may explain the excess wound contraction associated with these lesions. The present study examined the activity of fibroblasts derived from hypertrophic scar (HTS) in FPCL contraction to document changes in fibroblast-collagen interaction, which might explain the clinical scar contraction. Because transforming growth factor- $\beta$ (TGF- $\beta$ ) has been implicated in the phenotypic changes of hypertrophic fibroblasts, the role of endogenous TGF- $\beta$ in modulating FPCL contraction was also examined.

\section{MATERIALS AND METHODS}

\section{Patient characteristics}

Hypertrophic skin and normal skin (NS) were excised from patients with hypertrophic scars after burn injury (Table 1). Full-thickness skin samples were removed from three patients at the time of four reconstructive surgical procedures, 1 to 2 years after burn injury. These scars were red, increasing or stable in size, with symptomatic itching or pain. These lesions were actively contracting at the time of removal, as was evidenced by clinically symptomatic contractures which were not responding to nonoperative therapeutic interventions. An additional skin sample was obtained from a patient 4 years after burn injury, a time period when wound contraction had ceased. Biopsy specimens ranged in size from 20 to $80 \mathrm{~cm}^{2}$. Normal, uninjured full-thickness skin from adjacent tissue of each patient was also obtained and used as a source of control fibroblasts.

The study protocol for this investigation was approved by the University of Michigan human research review committee (IRB 91-78), thereby ensuring compliance with the ethical guidelines of the 1975 Declaration of Helsinki.

Tissue biopsy specimens were also obtained from 10 patients (mean age $25 \pm 16$ years) with clinical HTS 7 to 24 months (mean $17.2 \pm 6.8$ months) after thermal injury to determine the TGF- $\beta$ production in intact tissues. Full-thickness punch biopsy specimens (6 mm diameter) of HTS and NS were obtained at the time of reconstructive procedures. Biopsy specimens were incubated for 16 to 20 hours in $3 \mathrm{ml}$ MCDB 110 medium (Sigma Chemical Co., St. Louis, Mo.) with $0.2 \mathrm{mg} / \mathrm{ml}$ bovine serum albumin. The conditioned media were then aliquoted and stored at $-70^{\circ} \mathrm{C}$.

\section{Cell populations}

The excised skin samples were treated for 1 to 2 hours with gentamicin $20 \mathrm{mg} / \mathrm{L}$ and amphotericin B $2 \mathrm{mg} / \mathrm{L}$. The biopsy specimens were then incubated overnight in $0.15 \%$ trypsin at room temperature. The following morning the epidermis was mechanically disrupted from the underlying dermis by scraping with a scalpel blade and used for other studies. The dermal remnant was rinsed with phosphate-buffered saline solution, minced into 1 to $2 \mathrm{~mm}$ pieces, and treated with filter-sterilized crude collagenase $1 \mathrm{mg} / \mathrm{ml}$ (Sigma Chemical Co.) for 2 hours at room temperature. After nylon mesh filtration, the cells were plated at 1 to $2 \times$ $10^{6}$ cells/T-75 flask in MCDB 110 medium (Sigma Chemical Co.) supplemented with $5 \%$ fetal bovine serum (FBS). The MCDB 110 medium was modified for use in a $5 \% \mathrm{CO}_{2}$ incubator by the addition of $50 \mathrm{mmol}$ $\mathrm{L} \mathrm{Na}_{2} \mathrm{CO}_{3}$, and the $\mathrm{pH}$ was adjusted to 7.1. The cells were grown to confluence at passage 0 and then serially passaged by brief trypsinization with a $1: 3$ split. These cells resemble typical fibroblasts morphologically and synthesize types I and III collagen (data not shown. 
Some cells were stored at $-195^{\circ} \mathrm{C}$ in $20 \%$ serum and $10 \%$ dimethyl sulfoxide for future studies. All studies were performed on cells at either passage 3 or 4 .

\section{Fibroblast-populated collagen lattices}

FPCL were manufactured as previously described..$^{20}$ The collagen used to fabricate FPCL was extracted from rat tail tendon collagen by acetic acid extraction and sodium chloride salt precipitation. The purified collagen was dialyzed, frozen, lyophilized, and stored at $5 \mathrm{mg} / \mathrm{ml}$ in $1 \mathrm{mmol} / \mathrm{L} \mathrm{HCl}$ at $4^{\circ} \mathrm{C}$ as a viscous solution.

Triplicate $0.5 \mathrm{ml}$ samples of trypsinized HTS or NS fibroblasts at a density of $2 \times 10^{5}$ cells $/ \mathrm{ml}$ were each added to $1 \mathrm{ml}$ of Dulbecco's modified Eagle medium supplemented with $10 \%$ FBS and $0.5 \mathrm{ml}$ of collagen solution, rapidly mixed, and immediately poured onto $35 \mathrm{~mm}$ diameter petri dishes. The collagen polymerized in less than 90 seconds. The diameter of each FPCL was measured daily on the major and minor meridian with a ruler to the nearest $0.5 \mathrm{~mm}$. Lattice area (AREA) was calculated with the formula: AREA $=\pi[($ major meridian/2) (minor meridian/2)]

\section{Cytokine and antibody treatment}

To examine the effects of TGF- $\beta$ on FPCL contraction, $10 \mathrm{ng} / \mathrm{ml}$ (final concentration) of recombinant human TGF- $\beta_{1}$ (R\&D Systems, St. Paul, Minn.) was added to the cell-containing media just before mixing with the collagen solution for fabrication of the HTS or NS fibroblast-populated lattices. Control lattices received the same volume of buffer. The lattices were then allowed to contract, and the rate of contraction was quantified as described previously.

Three additional sets of FPCL were fabricated with and without a polyclonal anti-TGF- $\beta$ antibody, which recognizes the TGF- $\beta_{1}, \mathrm{TGF}-\beta_{2}$, and TGF- $\beta_{3}$ isotypes (Genzyme, Cambridge, Mass.). The antibody was added to each gel during fabrication as described here for TGF- $\beta$, resulting in a final concentration of $10 \mathrm{mg} /$ ml. No further antibody was added to the FPCL during the contraction period. To conserve antibody, we fabricated these lattices in smaller culture dishes measuring $15 \mathrm{~mm}$ in diameter and contraction was quantified as described previously for the larger dishes. Nonimmune antibody was not added to control lattices because this procedure has previously been shown to have no effect on the contraction of FPCL. ${ }^{33}$

\section{TGF- $\beta$ assay}

TGF- $\beta$ was quantified by means of the mink epithelial cell assay. ${ }^{34}$ Nonconfluent My 1 Lu mink lung epithe-
Table 2. Comparison of neonatal foreskin and normal skin FPCL contraction

\begin{tabular}{lccc}
\hline & \multicolumn{3}{c}{ FPCL area $\left(\mathbf{m m}^{2}\right)$} \\
\cline { 2 - 4 } Fibroblast type & Day 1 & Day 2 & Day 8 \\
\hline Neonatal foreskin & $488 \pm 58$ & $255 \pm 71$ & $145 \pm 119$ \\
Normal skin & $692 \pm 192$ & $373 \pm 129$ & $150 \pm 79$ \\
\hline
\end{tabular}

"Time of incubation after polymerization of the collagen gel.

lial cells (CCL-64; American Type Culture Collection, Rockville, Md.) were plated at $2.5 \times 10^{5} \mathrm{cells} / \mathrm{ml}$ in 96 well plates in Dulbecco's modified Eagle medium supplemented with $2 \%$ FBS. Conditioned medium with or without anti-TGF- $\beta$ antibody or nonimmune immunoglobulin $\mathrm{G}$ was added and incubated for 22 hours. ${ }^{3} \mathrm{H}$-thymidine $(1 \mu \mathrm{Ci} /$ well) (sp act. $60 \mathrm{Ci} / \mathrm{mmol}$; ICN Biomedicals, Inc., Costa Mesa, Calif.) was added for a 2 -hour pulse. The medium was then removed, and the cell layer was trypsinized and transferred to glass filter paper with the use of an automated cell harvester. A reference sample of $0.1 \mathrm{ng}$ of TGF- $\beta$ was included with each assay as a standard.

\section{Statistical analysis}

Contraction data were analyzed in two manners. Statistical comparisons of group FPCL area mean values for each time point were performed by means of analysis of variance. When significant differences were found, post hoc testing for multiple comparisons was done with the Tukey method. The relative rates of contraction were compared by means of regressions of the FPCL areas. The data were log-transformed when this comparison resulted in increased linearity. The resulting slopes were compared by means of an analysis to determine parallelism. Significant differences between contraction rates were considered to be present if the resulting $\mathrm{T}$ value represented an $\alpha$ value of less than $0.01 .^{35}$

\section{RESULTS}

The pertinent clinical characteristics of the patient population from which the HTS and NS cells were derived are summarized in Table 1. When NS cells from these patients were incorporated into collagen lattices, they caused contraction of the lattice at a rate that was initially somewhat slower than that induced by neonatal foreskin fibroblasts (Table 2). At the end of 8 days, however, the neonatal foreskin and NS fibroblasts had contracted their respective lattices to $15 \%$ and $14 \%$ of initial area, respectively. These data confirm that the NS-derived fibroblasts used as a control caused FPCL contraction at rates which are com- 


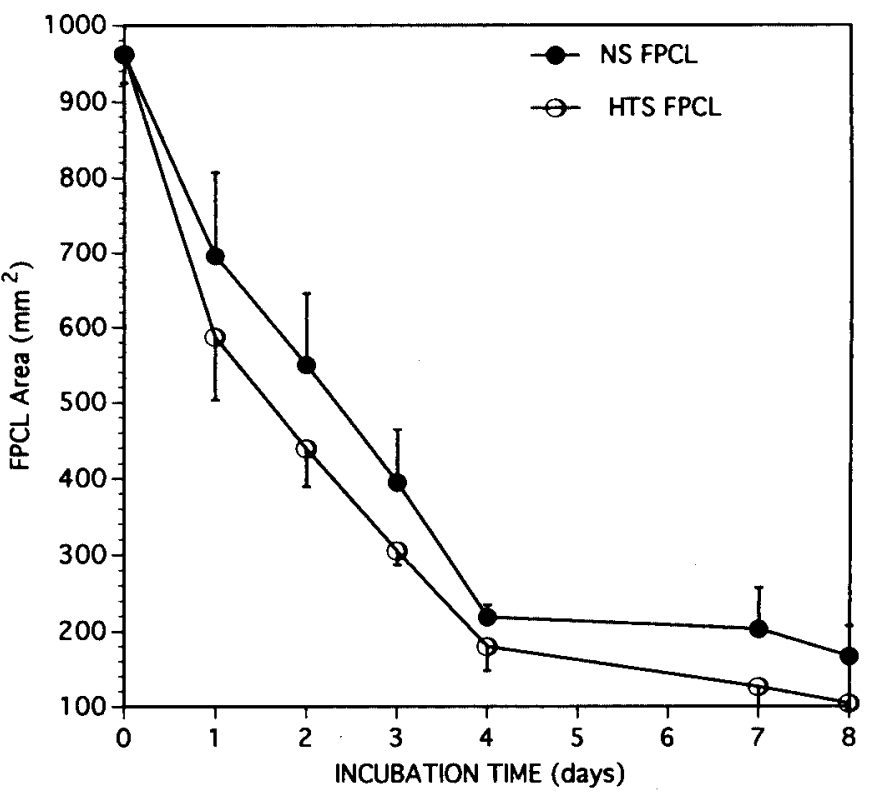

Figure 1 Contraction rates of NS and active scar HTS FPCLS. Collagen lattices populated with NS or HTS fibroblasts derived from actively contracting scars (15 to 24 months after injury) were made. At the indicated times after gelation, the lattice areas were measured and expressed as mean \pm standard deviation of triplicate experiments ( $n=4$, cells were from four different patient samples) HTS fibroblasts induce contraction at a significantly faster rate than NS cells (linear regression of log-transformed slopes, test for parallelism, $p<0.01$ ). In addition, there is a significantly smaller area of FPCL populated with HTS than with NS cells at each day shown ( $p<$ 0.05 , analysis of variance, post hoc testing with the Tukey method).

parable with those observed with normal foreskin fibroblasts. Moreover, these data show that the differences in contraction by HTS-populated FPCL are not due to changes within the normal cells of these patients.

To determine whether increased contractility of HTS is associated with an increased ability of H'TSderived fibroblasts to contract collagen lattices, the lattice contraction rates of NS and HTS fibroblasts from four cell strains with active young scars (<24-monthold burn scar) were compared. Plotting of lattice area as a function of time after gelation showed a significantly increased rate of contraction by HTS versus NS cells for each patient's cells examined, although the magnitude of the difference in contraction rate between HTS and NS cells varied among patients. The results from grouping the data from all four patients during the initial rapid contraction period are shown in Figure 1 . Both cell types induce rapid contraction of the lattice during the initial 4 days after lattice formation, resulting in area decreases of $18 \%$ and $29 \%$ on day 1 , $59 \%$ and $69 \%$ on day 3 , and $79 \%$ and $87 \%$ for day 7 for NS and HTS lattices, respectively. Significant differences in FPCL area for these two cell types persist during a 13-day period for both pooled and individual data.

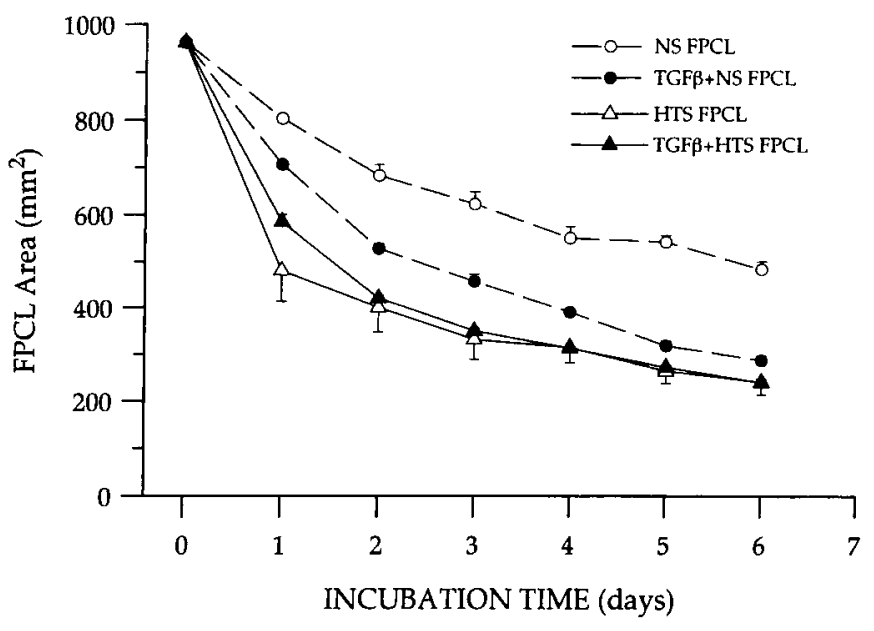

Figure 2 Effects of TGF-B on NS and HTS FPCL contraction. NS and HTS fibroblasts were obtained from one patient with active scar and incorporated into FPCLs in the presence or absence of 10 $\mathrm{ng} / \mathrm{ml}$ recombinant human TGF- $\beta$, Lattice areas were then measured at the indicated time points after lattice gelation, and data were expressed as the mean of triplicate experiments \pm standard deviation. The contraction of TGF- $\beta$-stimulated NS FPCLs was significantly accelerated relative to untreated NS FPCL (linear regression, test for parallelism, $p<0.01$ ), with significantly decreased lattice areas at days 2 to $6(p<0.05$, analysis of variance, post hoc testing with the Tukey method). In contrast, the contraction rate of HTS cells is not significantly altered by TGF- $\beta$ treatment. When TGF- $\beta$-treated NS FPCLS were compared with untreated HTS FPCL, the areas at the completion of the contraction period were similar ( $p=0.16$, analysis of variance, post hoc testing with the Tukey method).

To confirm that the differences in contraction shown in Figure 1 are the result of a change in the rate of contraction rather than only from a change in the contraction rate at day 1 , we compared the relative rates (slopes) of contraction for each cell type by means of regression analysis. The area values were log-transformed to increase linearity and compared by means of linear regression. Regressions of the log-transformed areas by day yielded slopes of -0.259 for NS and -0.341 for HTS ( $p<0.05, t$-test for parallelism). These differences in slope support the conclusion that the rate of contraction induced by HTS is greater.

In contrast to these differences between HTS and NS FPCL contraction rates in donors with young, active scars, fibroblasts derived from one patient with an older and quiescent scar (84-month-old burn scar) did not show any significant difference between contraction induced by NS cells and HTS cells with the use of either method of analysis (data not shown). Both cell populations contracted FPCL at virtually the same rate for all time points examined.

Because TGF- $\beta$ is known to modulate FPCL contraction, the effects of TGF- $\beta$ on the contraction of collagen lattices populated with HTS and NS fibro- 


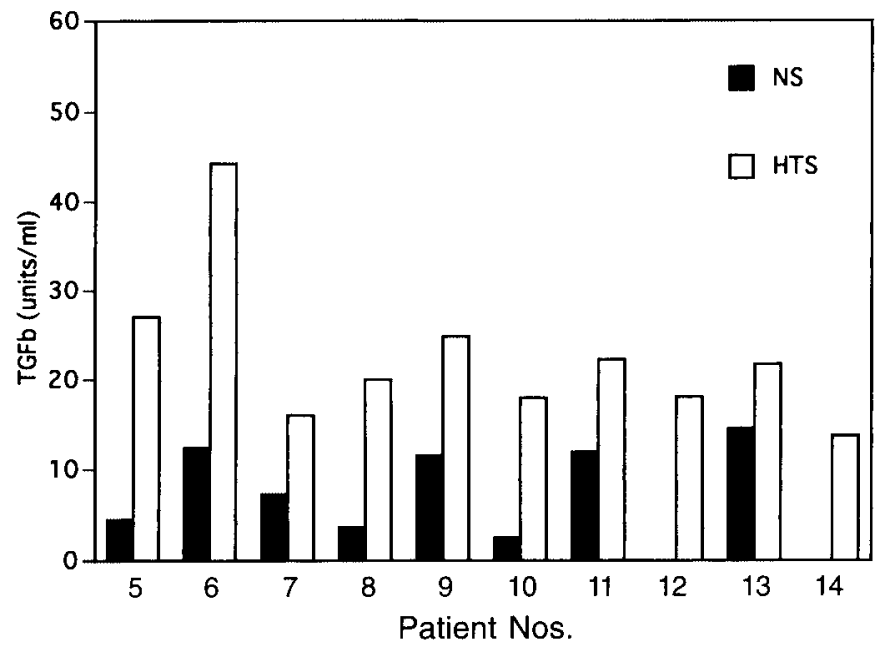

Figure 3 TGF- $\beta$ activity in tissue biopsy specimens of NS and HTS. Punch biopsy specimens $\left(6 \mathrm{~mm}^{2}\right.$ of normal and hypertrophic skin were incubated in MCDB 110 medium for 18 hours. The resulting conditioned media were assayed for TGF- $\beta$ content with the use of the mink epithelial cell proliferation assay. In all cases, the TGF$\beta$ content was greater in the HTS-conditioned media $(p=0.00$ ) analysis of variance).

blasts were compared. In the presence of $10 \mathrm{ng} / \mathrm{ml}$ of $\mathrm{TGF}$, the rate of contraction increased significantly for NS FPCL (Figure 2) $(p<0.01$, regression analysis and test for parallelism). The lattice areas at the last day of contraction, day 6 , were similar for the TGF- $\beta$ treated NS FPCL and the HTS FPCL, with or without treatment $(p=0.16)$. In contrast, the untreated NS FPCL were significantly larger $(p<0.01)$. These results suggest that increased endogenous production of TGF- $\beta$ by the HTS fibroblasts may result in increased lattice contraction. To examine this possibility, we determined the effect of specific antibody to TGF- $\beta$ on FPCL contraction. Treatment of both NS and HTS FPCLs with anti-TGF- $\beta$ antibody resulted in significant decreases in the rate of lattice contraction (Table 3), supporting our conclusion that TGF- $\beta$ mediates the differences in contraction rates between HTS and NS FPCL.

The results of these experiments suggested that increased endogenous release of or increased sensitivity to TGF- $\beta$ would provide a mechanism for increased contraction induced by HTS cells. Because the original fibroblast cell populations had been fully used in the preceding experiments, TGF- $\beta$ production by HTS and NS tissue was determined with the use of an additional series of 10 patients. The mean age of these patients was 22 years, and the biopsies were performed a mean of 15 months after their injury. TGF- $\beta$ activity in these biopsy specimens was significantly greater from HTS biopsy specimens: $22.5 \pm 8.7 \mathrm{ng} / \mathrm{ml}$ versus $6.8 \pm 5.4 \mathrm{ng} / \mathrm{ml}$ than from NS biopsy specimens $(p<$
Table 3. Contraction after treatment with anti-TGF- $\beta$ antibody

\begin{tabular}{lcc}
\hline & \multicolumn{2}{c}{ Contraction rate $\left(\Delta\right.$ area $\left[\mathbf{m m}^{2} /\right.$ day $\left.]\right)$} \\
\cline { 2 - 3 } Cell type & Control & Anti-TGF $-\beta$ antibody \\
\hline NS & $-12.8 \pm 1.1$ & $-9.6 \pm 1.3^{2}$ \\
HTS & $-14.1 \pm 0.6$ & $-11.1 \pm 1.1$ \\
\hline
\end{tabular}

"Significant difference from control (test for parallelism, $p<0.05$ ).

0.001 , analysis of variance). Although a marked variability exists between the relative TGF- $\beta$ production by each biopsy, in all cases TGF- $\beta$ activity was greater in the HTS tissue (Figure 3).

\section{DISCUSSION}

Wounds heal by a combination of processes including wound contraction, reepithelialization, granulation, and scar deposition. The relative contribution of these factors varies with the individual wound, etiologic status of the wound, and patient. Frequently, healing after burn injury is abnormal and results in excess matrix production, the development of HTS, and subsequent scar contraction. The mechanism whereby normal wound healing becomes, characteristically, deranged and these normal wound healing activities become exaggerated is not fully understood. Previous work has suggested that excess matrix production after thermal injury is due to a phenotypic change of the cells within the wound to cells likely to deposit excess scar. The contraction of collagen gels by fibroblasts provides an opportunity to study the mechanisms for increased wound contraction and scar contracture. Contraction of the FPCL reflects remodeling of collagen by wound fibroblasts and the rate of contraction is influenced by the chemical composition of the gel, ${ }^{2,36}$ the physiologic state of the fibroblasts, ${ }^{20,37-42}$ and cytokines. ${ }^{17,27,29,43,44}$ Previous studies of wound contraction after burn injury have implicated changes in matrix protein in its causation. HTS tissues contain altered ratios of type I and III collagen, as well as minor collagens. ${ }^{20,45,46}$ Because creation of FPCL with type III collagen results in accelerated contraction, ${ }^{23}$ HTS which contain more of this protein are likely to contract more. The findings of this report add intrinsic differences in fibroblast contraction rates and suggest changes in the cytokine environment of the wound as additional mechanisms for the clinical events. These factors together might explain the aggressive contraction diathesis seen in postburn scar contractures.

The influence of TGF- $\beta$ on FPCL contraction has been reported previously. ${ }^{27,29}$ This relationship is supported in the present study by the ability of TGF- $\beta$ to 
stimulate NS FPCL contraction and by the inhibition of FPCL contraction by anti-TGF- $\beta$ antibody. Furthermore, because antibody treatment reduced the higher contraction rate of HTS FPCL to a level approaching that of NS FPCL, it is likely that the increased contraction induced by HTS fibroblasts is due to enhanced autocrine stimulation by increased levels of endogenous TGF- $\beta$ production by HTS cells. This hypothesis is supported by the finding of increased release TGF- $\beta$ by HTS biopsy specimens. Alternatively or additionally, the increased rate of FPCL contraction by HTS cells may be due to an increased sensitivity to the TGF- $\beta$ in FBS used in the assay media.

Our ability to perform these experiments was limited by the low frequency of patients with these lesions who are surgical candidates during early scar maturation. The cell populations for these studies were derived from mature, but active, HTS, as defined by time after initial burn injury and clinical symptoms such as ongoing wound contraction, erythema, and itching. One older case was from a significantly older scar which was quiescent, pale, and asymptomatic. These clinical differences between these lesions were reflected in differences between HTS and NS contraction rates; that is, cells cultured from the quiescent scar were not different from NS fibroblasts isolated from the same donor. This finding suggests an evolution of cell contractile phenotype within the burn wound lesion which characterizes the stages of HTS formation as manifested by clinical signs and symptoms. In addition, the cell populations used for these studies were obtained from clinical specimens of limited tissue, and, therefore, limited numbers of fibroblasts were available for study. Although it is possible to expand fibroblast cell lines greatly, experiments have determined that the phenotype differences between HTS and NS are lost by culture beyond passage 4 (data not shown). Because the HTS cells grow slowly, ${ }^{32}$ serial passage likely results in overgrowth by clones which responds to the tissue culture environment. The results presented in this article reflect the limited number of early passage fibroblasts which are available for study.

Previous investigations of the contractile properties of HTS fibroblasts suggested that these cells were not different from normal dermal fibroblasts in their ability to contract collagen. ${ }^{47}$ The present findings appear to contradict these previous conclusions. Although the reason for this discrepancy or contradiction is unclear at this time, the variability of contraction rates between patients and the modest difference between HTS and NS fibroblasts suggest an explana- tion. The former studies did not use patient-matched comparisons between HTS and NS cells. The heterogeneity of individual responses hides the increased contraction shown by the HTS cells. Furthermore, in older inactive or quiescent scars, no significant difference was found in lattice contraction rates. Pooling or grouping results from experiments using cells derived from scars of various ages, and activity may have further diluted the differences between HTS and NS FPCL contraction rates. Finally, the passage number of the fibroblasts used in the previous study was greater than 3. Thus, it is possible that in previous studies the differences documented in these patientmatched populations were lost because of intersubject variability, heterogeneity in scar activity, age, or overexpansion of the cell strains resulting in the loss of a distinct scar phenotype.

\section{ACKNOWLEDGMENTS}

This work was supported in part by National Institutes of Health grants Nos. HL28737, HL31963, and DK46469. The excellent technical assistance of Jenelda Lynch and Cyndi Zuccaro, statistical support and expertise of Ron Dechert, and secretarial support of Susan Harbison is gratefully acknowledged.

\section{REFERENCES}

1. Andujar MB, Melin M, Guerret S, Grimaud JA. Cell migration influences collagen gel contraction. J Submicrosc Cytol Pathol 1992;24:145-54.

2. Boyce ST, Christianson DJ, Hansbrough JF. Structure of a collagen-GAG dermal skin substitute optimized for cultured human epidermal keratinocytes. J Biomed Mat Res 1988;22:939-57.

3. Boyce ST, Hansbrough JF. Biologic attachment, growth, and differentiation of cultured human epidermal keratinocytes on a graftable collagen and chondroitin-6-sulfate substrate. Surgery 1988;103:421-31.

4. Ingber DE, Folkman J. Mechanochemical switching between growth and differentiation during fibroblast growth factorstimulated angiogenesis in vitro: role of extracellular matrix. J Cell Biol 1989;109:317-30.

5. Mauch C, Hatamochi A, Scharffetter K, Krieg T. Regulation of collagen synthesis in fibroblasts within a three-dimensional collagen gel. Exp Cell Res 1988;178:493-503.

6. Mustoe TA, Pierce GF, Morishima C, Deuel TF. Growth factorinduced acceleration of tissue repair through direct and inductive activities in a rabbit dermal ulcer model. J Clin Invest 1991;87:694-703.

7. Nakagawa S, Pawelek P, Grinnell F. Extracellular matrix organization modulates fibroblast growth factor responsiveness. Exp Cell Res 1989;182:572-82.

8. Opas M. Expression of the differentiated phenotype by epithelial cells in vitro is regulated by both biochemistry and mechanics of the substratum. Dev Biol 1989;131:281-93.

9. Sarubbi DJ, Narayanan R, Telang NT, Newman MJ. Evaluation of the role of extracellular matrix proteins, polyunsaturated fatty acids and C-MYC expression in the inhibition of the se- 
rum-free growth of epithelial cells by TGF- $\beta 1$. In Vitro Cell Dev Biol 1990;26:1195-201.

10. Tinois E, Faure M, Chatelain P, Vallier P, Schmitt D. Growth and differentiation of human keratinocytes on extracellular matrix. Arch Dermatol Res 1987;279:241-6.

11. Watt FM. The extracellular matrix and cell shape. TIBS $1986 ; 11: 482-5$.

12. Woodley D'T, Wynn KC, O'Keefe EJ. Type IV collagen and fibronectin enhance human keratinocyte thymidine incorporation and spreading in the absence of soluble growth factors. $\mathrm{J}$ Invest Dermatol 1990;94:139-43.

13. Majno G, Gabbiani G, Hirschel BJ, Ryan GB. Contraction of granulation tissue in vitro: similarity to smooth muscle. Science $1971 ; 173: 548-50$

14. Bell E, Ivanson B, Merrill C. Production of a tissue-like structure by contraction of collagen lattice by human fibroblasts of different proliferative potential in vitro. Proc Natl Acad Sci U S A 1979;76:1274-8.

15. Rudolph R, Vande Berg J, Ehrlich HP. Wound contraction and scar contracture. In: Cohen IK, Diegelmann RF, Lindblad WJ, editors. Wound healing. Biochemical and clinical aspects. Philadelphia: WB Saunders, 1992:96-114.

16. Guidry C, Grinnell F. Studies on the mechanism of hydrated collagen gel reorganization by human skin fibroblasts. J Cell Sci 1985;79:67-81.

17. Rittenberg T, Burd DAR, Ehrlich HP. Soluble factor(s) in rat wound fluid inhibit fibroblast populated lattice contraction. Exp Mol Path 1990;52:132-40.

18. Anderson SN, Ruben Z, Fuller GC. Cell-mediated contraction of collagen lattices in serum free medium: effect of serum and nonserum factors. In Vitro Cell Dev Biol 1990;26:61-6.

19. Asaga $H$, Kikuchi S, Yoshizato $K$. Collagen gel contraction by fibroblasts requires cellular fibronectin but not plasma fibronectin. Exp Cell Res 1991;193:167-74.

20. Butfie DJ, Ehrlich HP. Comparative studies of collagen lattice contraction utilizing a normal and a transformed cell line. $J$ Cell Physiol 1983;116:159-66.

21. Clark RAF, Folkvord JM, Hart CE, Murray MJ, McPherson JM. Platelet isoforms of platelet-derived growth factor stimulate fibroblasts to contract collagen matrices. J Clin Invest 1989;84: 1036-40.

22. Ehrlich HP, Griswhold TR, Rajaratnam JBM. Studies on vascular smooth muscle cells and dermal fibroblasts in collagen matrices: effects of heparin. Exp Cell Res 1986;164:154-62.

23. Ehrlich HP. The modulation of contraction of fibroblast populated collagen lattices by types I, II and III collagen. Tissue Cell 1988;20:47-50

24. Gillcry P, Maquart FX, Borel JP. Fibronectin dependence of the contraction of collagen lattices by human skin fibroblasts. Exp Cell Res 1986;167:29-37.

25. Guidry C, Grinnell F. Heparin modulates the organization of hydrated collagen gels and inhibits gel contraction by fibroblasts. J Cell Biol 1987;104:1097-103.

26. Guidry C, McFarland RJ, Morris R, Witherspoon CD, Hook M. Collagen gel contraction by cells associated with proliferative vitreoretinopathy. Ophthalmol Vis Sci 1992;33:2429-35.

27. Montesano R, Orci L. Transforming growth factor beta stimulates collagen-matrix contraction by fibroblasts: implications for wound healing. Proc Natl Acad Sci U S A 1988;85:4894-7.

28. Norris WD, Steele JG, Johnson G, Underwood PA. Serum enhancement of human endothelial cell attachment to and spreading on collagens I and IV does not require serum fibronectin or vitronectin. J Cell Sci 1990;95:255-62.
29. Tingstrom A, Heldin CH, Rubin K. Regulation of fibroblastmediated collagen gel contraction by platelet-derived growth factor, interleukin-1 and TGF-ß31. J Cell Sci 1992;102:315-22.

30. Woodley DT, Yamauchi M, Wynn KC, Mechanic G, Briggaman RA. Collagen telopeptides (cross-linking sites) play a role in collagen gel lattice contraction. J Invest Dermatol 1991;97:580-5.

31. Helm PA. Burn rehabilitation: dimensions of the problem. In: Salisbury RE, editor. Clinics in plastic surgery. Philadelphia: WB Saunders, 1992:551-9.

32. Garner WG, Karmiol S, Rodriguez JL, Smith DJ Jr., Phan SH. Phenotypic differences in cytokine responsiveness of hypertrophic scar versus normal dermal fibroblasts. J Invest Dermatol 1993;101:1-5.

33. Klein CE, Dressel D, Steinmayer T, Mauch C, Eckes B, Krieg $T$, Bankert RB, Weber L. Integrin alpha 2 beta 1 is upregulated in fibroblasts and highly aggressive melanoma cells in threedimensional collagen lattices and mediates the reorganization of collagen I fibrils. J Cell Biol 1991;115:1427-36

34. Danielpour D, Dart LL, Flanders KC, Roberts AB, Sporn MB. Immunodetection and quantitation of the two forms of transforming growth factor-beta (TGF- $\beta 1$ and TGF- $\beta 2$ ) secreted by cells in culture. J Cell Physiol 1989;138:79-86.

35. Kleinbaum D, Kupper L, Mullen B. Applied regression analysis and other multivarient methods. 2nd edition. Boston: PWS-Kent, $1987 \cdot 262-8$

36. Ehrlich HP, Brown H, White BS. Evidence for type V and I trimer collagens in Dupuytren's contracture palmar fascia. Biochem Med 1982;28:273-84.

37. Adams LW, Priestley GC. Contraction of collagen lattices by skin fibroblasts from dystrophic recessive epidermolysis bullosa and other dermatoses. J Invest Dermatol 1988;87:544-6.

38. Ehrlich HP, Butfie DJ, Trelstad RL, Hayashi K. Epidermolysis bullosa dystrophica recessive fibroblasts altered behavior within a collagen matrix. J Invest Dermatol 1986;80:56-60.

39. Ehrlich HP, Butfie DJ, Bernanke DH. Physiological variables affecting collagen lattice contraction by human dermal fibroblasts. Exp Mol Pathol 1989;50:220-9.

40. Hembry RM, Bemank DH, Hayakashi K, Trelstad RL, Ehrlich HP. Morphologic examination of mesenchymal cells in healing wounds of normal and tight skin mice. Am J Pathol 1986; 125:81-9.

41. Porras-Reyes BH, Blair HC, Jeffrey JJ, Mustoe TA. Collagenase production at the border of granulation tissue in a healing wound: macrophage and mesenchymal collagenase production in vivo. Connect Tissue Res 1991;27:63-71.

42. Ehrlich HP, Wyler DJ. Fibroblast contraction of collagen lattices in vitro: inhibition by chronic inflammatory cell mediators. J Cell Physiol 1983;116:345-51.

43. Gullberg D. Tingstrom A, Thuresson AC, Olsson L, Terracio L, Borg TK, Rubin K. Beta 1 integrin-mediated collagen gel contraction is stimulated by PDGF. Exp Cell Res 1990;186: 264-72.

44. Gillcry P, Coustry F, Pujol JP, Borel JP. Inhibition of collagen synthesis by interleukin-1 in three-dimensional collagen lattice cultures of fibroblasts. Experientia 1989;45:98-101.

45. Hayakawa T, Hashimoto Y, Myokai Y, Aoyama H, Izawa Y Changes in type of collagen during the development of human post-burn hypertrophic scars. Clin Chim Acta 1979;93:119-25.

46. Hashimoto Y, Shieh TY, Aoyama H, Izawa Y, Hayakawa T. Isolation and characterization of type $\mathrm{V}$ collagen from human postburn granulation tissues. J Invest Dermatol 1986;87:540-3.

47. Ehrlich HP. The role of connective tissue matrix in wound healing. Prog Clin Res 1988;266:243-58. 